\title{
Blood Osmoregulation and Ultrastructure of the Gas Windows ('Tympana') of Intertidal Ocypodid Crabs: Dotilla vs. Scopimera
}

\author{
Masatoshi Matsumasa $^{1)}$, Susumu Kikuchi ${ }^{1)}$, Satoshi Takeda ${ }^{2)}$, Sombat Poovachiranon ${ }^{3)}$, \\ Hoi-Sen Yong ${ }^{4)}$ and Minoru Murai ${ }^{5)}$ \\ 1) Department of Biology, School of Liberal Arts and Sciences, Iwate Medical University, \\ Honcho-dori 3-16-1, Morioka 020-0015, Japan \\ ${ }^{2)}$ Marine Biological Station, Faculty of Science, Tohoku University, Asamushi, Aomori 039-3501, Japan \\ ${ }^{3)}$ Phuket Marine Biological Center, Phuket 83000, Thailand \\ ${ }^{4)}$ Department of Zoology, Faculty of Science, University of Malaya, 59100, Kuala Lumpur, Malaysia \\ ${ }^{5)}$ Sesoko Station, Tropical Biosphere Research Center, University of the Ryukyus, 3422 \\ Sesoko, Motobu, Okinawa 905-0227, Japan
}

\begin{abstract}
Intertidal ocypodid crabs of the two genera Dotilla and Scopimera have unique membranous windows ('tympana') on their legs for aerial gas exchange, and the former also has them on its thoracic sterna. The osmoregulatory capabilities of Dotilla myctiroides and Scopimera pilura in dilute external media were compared, and microstructure of their tympana was examined to clarify whether they have an osmoregulatory function as well as a respiratory one, because respiratory surfaces are probable sites for osmoregulation or of water/ion loss. Although both D. myctiroides and S. pilura were hyperosmoregulators, the former species was much the weaker in this respect. Histological results showed that the tympana have simple, thin respiratory epithelia in both of these species as well as S. proxima, which indicates that the tympana are probably sites of water/ion loss. The thicker cuticle in Scopimera species than in D. myctiroides may be an adaptive characteristic for maintaining blood osmolality in dilute media, and this was confirmed by silver staining, which indicated that the loss of $\mathrm{Cl}^{-}$through tympana was smaller in Scopimera than in Dotilla. However, at the same time, the longer blood/gas diffusion distance due to the thickened cuticle must result in lower efficiency of gas exchange. Hence, a trade-off between respiratory efficiency and water/ion retention is involved in the development of tympana. From this viewpoint, the presence/absence of tympana among species of the subfamily Dotillinae, which includes Dotilla and Scopimera, is reviewed with reference to some taxonomic and phylogenetic considerations.
\end{abstract}

Key words: blood/gas diffusion distance, cuticle thickness, Dotilla, ion/water permeability, osmoregulation, Scopimera, terrestrial adaptation, ultrastructure of tympanal epithelia

\section{INTRODUCTION}

Semi-terrestrial crabs of the family Ocypodidae provide interesting perspectives for considering the adaptation of aquatic invertebrates to life on land (Powers $\&$ Bliss 1983). These crabs mainly inhabit intertidal 
areas and exhibit a distinct zonation of genera and species that reflects their differing degrees of terrestriality. Reduced salinity due to freshwater inflows is one of the major problems faced by such semiterrestrial crabs. Since variation in salinity increases with height on the shore as the moderating influence of the tides diminishes, higher shore species have stronger physiological mechanisms to protect against salinity reduction/fluctuation than lower shore inhabitants (Macintosh 1979).

To address this problem, comparative studies of crustacean species, including semi-terrestrial crabs, have focused largely on the characteristics of respiratory organs (e.g., surface area and morphology) in relation not only to osmoregulatory but also respiratory functions. This is because respiratory surfaces, which require thin membranes for gas exchange, are likely to be more permeable to water and ions than other body surfaces (Greenaway 1988; Lockwood \& Bolt 1989). Some previous studies have revealed that the gill, a major respiratory organ of crustaceans, has iontransporting as well as respiratory functions in a variety of crustacean groups that encounter reduced salinity (Barra et al. 1983; Dickson et al. 1991; Farrelly \& Greenaway 1992; Kikuchi \& Matsumasa 1993a, b; Takeda et al. 1996a; Matsumasa et al. 1998; Tsubokura et al. 1998). However, little work has been done on other types of respiratory organs, although respiratory surfaces other than gills are seen in a variety of crustaceans (McLusky 1968; Bliss 1979; Maitland 1986; Maitland \& Maitland 1992; Kikuchi \& Matsumasa 1993a, 1995, 1997).

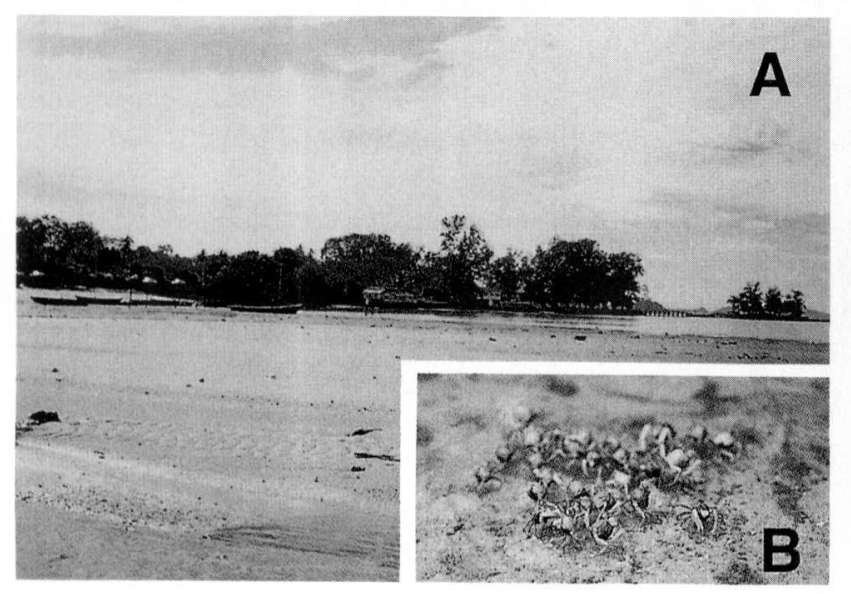

All members of the subfamily Dotillinae (Crustacea: Brachyura: Ocypodidae) except some species of Ilyoplax possess large membranous disks ('tympana') on the meral segment of the legs (Kemp 1919). Species of Dotilla and Scopimera that inhabit sandy shores have these tympana, and species of the former genus also have tympana on their thoracic sterna. Maitland (1986) carried out an excellent work on the function of tympana and revealed that the surfaces are primarily gas windows for aerial gas exchange. In the present study, we compare Dotilla myctiroides as a lower shore inhabitant and Scopimera spp. as a higher shore dweller (see Kemp 1919, Hartnoll 1973) in terms of their osmoregulatory capabilities in dilute external media and the microstructures of their tympana, in order to clarify whether the gas window also has an osmoregulatory function. In addition, we propose a functional reason for the restriction of this unique respiratory organ to only some semi-terrestrial crabs, namely, members of the Dotillinae, referring to previous taxonomic studies (Kemp 1919; Serene \& Lundoer 1974) and a recent phylogenetic analysis (Kitaura et al. 1998) of this subfamily.

\section{MATERIALS AND METHODS}

Animals were collected from sand flats at Port Dickson (Pantai), Negeri Sembilan, Malaysia, and in Phuket, Thailand. At Port Dickson, Dotilla myctiroides and Scopimera pilura were sympatrically distributed. The former species inhabited a bare sand substratum on the

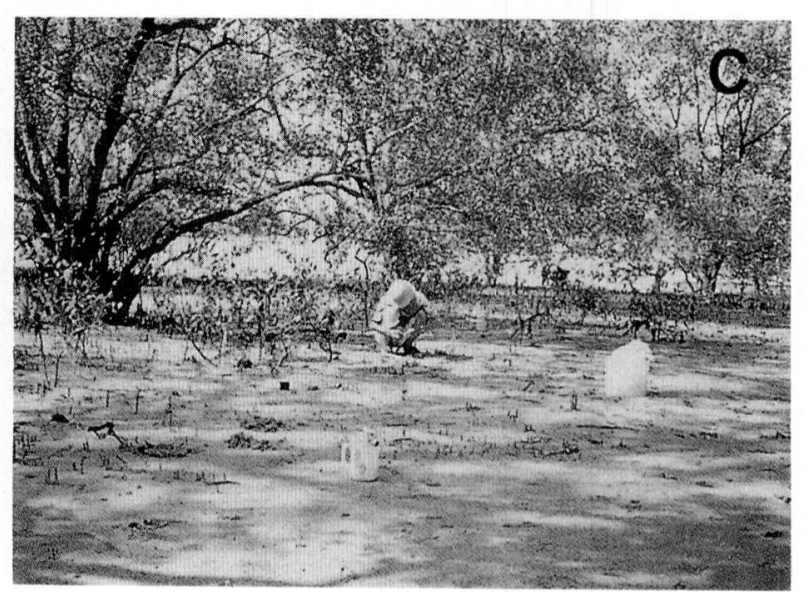

Fig. 1. The Port Dickson site, Malaysia ( $2^{\circ} 30^{\prime} \mathrm{N}$; $101^{\circ} 51^{\prime} \mathrm{E}$ ). Dotilla myctiroides inhabited the lower part of the shore (A). Many individuals of the species often left their burrows, wandered down to the shoreline, and fed in groups there. This behavior, referred to as 'droving' or 'herding', is characteristic for some ocypodid crabs including this species (B). Scopimera pilura was an upper-shore inhabitant, and its habitat was associated with sparse mangroves in this site (C). These photographs were taken in November, 1994. 
lower part of the shore, and the latter, a sand area with sparse mangrove vegetation higher up (Fig. 1; see also Takeda et al. 1996b). Dotilla myctiroides was also sampled at Ao Nam Bor and Ao Tang Khen, and S. pilura and S. proxima at Ban Pa Khloh and Sa Pan Hin, respectively, in Phuket. As on the Malaysian beach, $D$. myctiroides was observed in the lower parts of the tidal flats (see Matsumasa et al. 1992, Takeda et al. 1996a). Scopimera pilura and S. proxima inhabited the higher part of the sandy beaches, although these areas were not associated with mangroves.

Adult males of $D$. myctiroides (mean \pm SD of carapace length: $8.15 \pm 0.376 \mathrm{~mm} ; n=20$ ) and $S$. pilura (mean \pm SD of carapace length: $5.83 \pm 0.470 \mathrm{~mm} ; n=$ 20) from the Port Dickson site were used in an experiment to determine their blood osmoregulatory characteristics. Four individuals of each species of crab were placed in containers with $20,30,60,95$, and $100 \%$ seawater from Port Dickson. The depth of water was just $1 \mathrm{~cm}$, so the crabs were able to lift their bodies up into the air. After $18 \mathrm{hrs}$ (room temperature: $22.5 \pm 1$ ${ }^{\circ} \mathrm{C}$ ), blood samples (ca: $100 \mu \mathrm{l}$ ) were removed with a syringe from the arthrodial membrane at the base of the fourth ambulatory leg of each crab and allowed to clot. Osmolality of the serum and external water samples were determined using a freezing point microosmometer (Hermann Roebling, Type 13DR).

Permeable areas on the body surfaces were determined for D. myctiroides, S. pilura, and S. proxima from Phuket by a modified silver staining method (see Kikuchi \& Matsumasa 1993b). Living animals of the three species were quickly washed in changes of distilled water to remove any adherent salts and then immersed in $0.2 \mathrm{~N}$ nitric acid with $1 \%$ silver nitrate solution for 1 min. After removal of the excess silver nitrate by rinsing with distilled water, they were soaked in $0.2 \mathrm{~N}$ nitric acid for $5 \mathrm{~min}$. Then they were washed in distilled water again and put in a solution of photographic developer (Ilford) to blacken the permeable areas of the body surface by reduction of silver ions. The validity of this method for locating the regions of the body surface of crustaceans that are permeable to chloride ions had already been confirmed by element analyses using energydispersive X-ray microanalysis (EDX) (Kikuchi \& Matsumasa 1993b). In this study, the distribution of silver in the central areas $(80 \mu \mathrm{m} \times 100 \mu \mathrm{m})$ of the tympana was also examined using EDX and compared between Dotilla and Scopimera. The tympanal areas of the third ambulatory legs of silver-stained $D$. myctiroides and S. pilura were cut off, mounted on copper platelets, and then coated with carbon. These were analyzed by using a Hitachi H-600A scanningtransmission electron microscope equipped with a Kevex 8000 X-ray detector.

For morphological study, meral segments of the second and third ambulatory legs of the three species and sterna (for Dotilla only) were fixed in a mixed solution of $2.5 \%$ glutaraldehyde and $2 \%$ formaldehyde buffered with $0.2 \mathrm{M}$ phosphate at $\mathrm{pH}$ 7.4. They were rinsed several times in $0.2 \mathrm{M}$ phosphate buffer and then post-fixed for $1 \mathrm{hr}$ at room temperature in $2 \%$ osmium tetroxide in the same buffer solution. After dehydration in an ascending ethanol series, the specimens were embedded in an epoxy resin (Spurr). Ultrathin sections double-stained with uranylacetate and lead citrate were examined for five individuals of each of the three species with a JEOL JEM-100B transmission electron microscope. Epithelial and cuticle thicknesses were measured using a ruler at ten haphazardly selected places on photographs of the cross sections (magnification: $1 \times$ $\left.10^{4}\right)$ for each individual; their sum was referred to as the 'total blood/gas diffusion distances' across the tympana. Because a Bartlett test indicated heterogeneities in variances for the cuticle thickness and the blood/gas diffusion distance, $\log (x+1)$-transformed data were examined by ANOVA using SYSTAT (Wilkinson 1992). Bonferroni tests were done for multiple comparisons among means.

Energy-dispersive X-ray analysis was also used to compare the relative abundance of $\mathrm{Ca}$ as an index of cuticle calcification between tympanal areas of Dotilla and Scopimera. The tympanal areas and surrounding cuticles were cut from the third ambulatory legs of individuals of D. myctiroides and S. pilura that had been fixed in $70 \%$ ethanol. These were dried in air, mounted on copper platelets, and coated with carbon. After detecting the elements recognized as peaks, the elemental proportions in terms of atoms were calculated for $\mathrm{Mg}$, $\mathrm{Si}, \mathrm{P}, \mathrm{S}, \mathrm{Cl}, \mathrm{Ca}$, and $\mathrm{Fe}$ under the following conditions: acceleration voltage, $25 \mathrm{kV}$; beam current, $100 \mathrm{nA}$; and beam diameter, $1 \mu \mathrm{m}$. The differences in elemental proportion of $\mathrm{Ca}$ between analyzed areas (i.e. the tympanal and the surrounding areas of the two species) were examined by a $G$-test.

\section{RESULTS}

Eighteen hours after exposure to different salinities, none of the Dotilla survived at the lowest salinity (20\% SW), whereas three of four did at $30 \% \mathrm{SW}$ (Fig. 2). On the other hand, all the Scopimera survived in the 


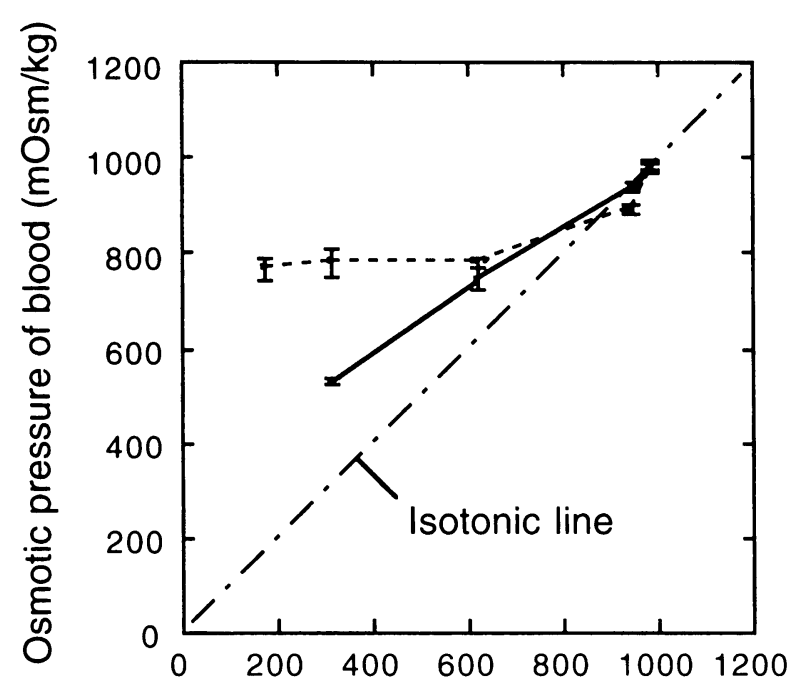

Osmotic pressure of medium ( $\mathrm{mOsm} / \mathrm{kg}$ )

Fig. 2. The blood osmolality controls of Dotilla myctiroides (solid line) and Scopimera pilura (dotted line). Vertical bars show $\pm \operatorname{SE}(n=4)$. The value for Dotilla is missing at $20 \% \mathrm{SW}(176 \mathrm{mOsm} / \mathrm{kg})$ and is based on three samples at $30 \% \mathrm{SW}(316 \mathrm{mOsm} / \mathrm{kg})$, since none survived at the lowest salinity and only three of four individuals survived at $30 \% \mathrm{SW}$.

various test salinities. Scopimera kept its blood osmolality much higher than the dilute external media of $176-622 \mathrm{mOsm} / \mathrm{kg}(20-60 \% \mathrm{SW})$ and became isotonic to the external media above $900 \mathrm{mOsm} / \mathrm{kg}$. Dotilla also maintained its hyperosmotic state in the dilute media, but its capability to do so was much lower than that of Scopimera. The blood osmolality of Dotilla was $531 \pm 7.0 \mathrm{mOsm} / \mathrm{kg}$ (mean $\pm \mathrm{SE}$ ) in an external medium of $316 \mathrm{mOsm} / \mathrm{kg}$, whereas that of Scopimera was $780 \pm 27.3 \mathrm{mOsm} / \mathrm{kg}$.
Tympana on both the meral segments of the legs and the thoracic sterna of Dotilla myctiroides were silver-stained more strongly than the surrounding areas (Fig. 3). In contrast, the tympana of the two species of Scopimera were scarcely stained at all. Energydispersive X-ray analysis for silver in the central areas (80 $\mu \mathrm{m} \times 100 \mu \mathrm{m}$ ) of the leg tympana clearly showed a difference in staining between $D$. myctiroides and $S$. pilura (Fig. 4). This confirmed that the permeability of the leg and sternal tympana of $D$. myctiroides to $\mathrm{Cl}^{-}$is higher than that of the leg tympana of S. pilura.

The histological examination revealed that the epithelia in the areas of the leg tympana of $D$. myctiroides and S. pilura are quite thin, with few mitochondria and neither apical nor basolateral infoldings of cell membranes. Under the thin epithelia, large hemocoels were observed (Fig. 5). A similar structure was observed for epithelia of the sternal tympana of $D$. myctiroides and of the leg tympana of S. proxima. These structural characteristics, being common to the tympana of the three species, suggest that these organs have a respiratory function both in Dotilla and Scopimera, but osmoregulatory one. Although the epithelial thickness of $S$. proxima is greater than those of the other species (Table 1; Bonferroni test, $P<0.001$ ), and that for $S$. pilura was greater than that of $D$. myctiroides $(P<$ 0.05 ), even the epithelia of Scopimera species were too thin to develop intracellular structures for iontransport, such as frequent membrane foldings and an abundance of mitochondria. However, the cuticle was much thicker in the two species of Scopimera than in $D$. myctiroides (Table 1; Bonferroni test, $P<0.001$ ), so the blood/gas diffusion distance across the tympana is greater for Scopimera than Dotilla $(P<0.001)$. Significant differences were also detected in cuticle thickness and blood/gas diffusion distance between the leg and sternal tympana of $D$. myctiroides $(P<0.001)$.

Table 1. Epithelial thickness, cuticle thickness, and total blood/gas diffusion distance ( $\mu \mathrm{m}$ ) across the tympana of Dotilla myctiroides and two species of Scopimera (mean $\pm \mathrm{SE}, n=5$ ). Values for leg tympana of the three species and for sternal ones of Dotilla were obtained from the 3rd ambulatory legs and from the 5th thoracic sternites, respectively. Carapace widths (mean $\pm \mathrm{SE}$ ) of crabs examined were $6.9 \pm 0.21 \mathrm{~cm}$ (Dotilla myctiroides), $6.6 \pm 0.04 \mathrm{~cm}$ ( $S$. pilura), and $5.1 \pm 0.04 \mathrm{~cm}$ (S. proxima). Underlines indicate no significant differences between means (Bonferroni test; $P>0.05$ ).

\begin{tabular}{|c|c|c|c|c|}
\hline \multirow[t]{2}{*}{ Region } & \multicolumn{2}{|c|}{ D. myctiroides } & \multirow{2}{*}{$\begin{array}{c}\text { S. pilura } \\
\text { leg }\end{array}$} & \multirow{2}{*}{$\begin{array}{c}\text { S. proxima } \\
\text { leg }\end{array}$} \\
\hline & leg & sternum & & \\
\hline Cuticle & $0.80 \pm 0.038$ & $1.63 \pm 0.040$ & $3.53 \pm 0.175$ & $3.85 \pm 0.087$ \\
\hline $\begin{array}{c}\text { Total } \\
\text { (blood/gas diffusion distance) }\end{array}$ & $0.90 \pm 0.037$ & $1.72 \pm 0.038$ & $3.65 \pm 0.179$ & $4.05 \pm 0.091$ \\
\hline
\end{tabular}



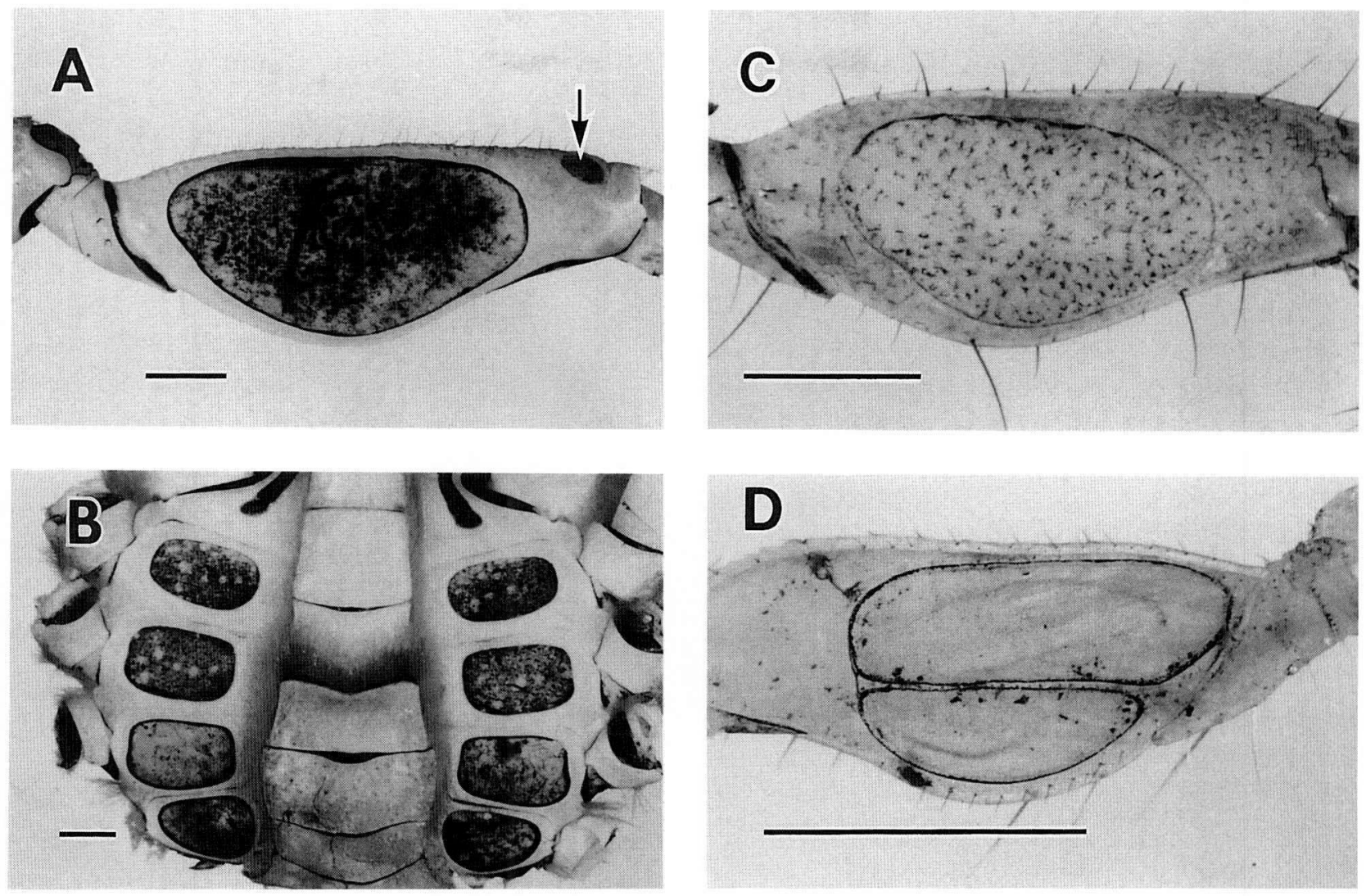

Fig. 3. Silver-stained tympana. The leg and sternal tympana of Dotilla myctiroides were darkly stained (A, B), but the leg tympana of Scopimera pilura (C) and S. proxima (D) were scarcely stained at all. (A) Posterior face of the meral segment of the 4th right ambulatory leg of D. myctiroides; the oval part (arrow) near the distal end of the meral segment is also darkly stained. Such oval parts are observed on the meral segments of all of the ambulatory legs. (B) Thoracic sternites of D. myctiroides. (C) Posterior face of the meral segment of the 4th right ambulatory leg of $S$. pilura. (D) Anterior face of the meral segment of the 4th right ambulatory leg of S. proxima; all of the tympana on the meral segments of the walking legs, with the exception of those on the posterior surfaces of the last pair of legs, are longitudinally divided by a narrow ridge. Scale bar $=1 \mathrm{~mm}$.

The patterns of elemental proportions in terms of atoms were quite similar for the leg tympana of Dotilla myctiroides and Scopimera pilura (Fig. 6), but they differed between the tympanal area and its surrounding cuticle in both species, the relative percentage of $\mathrm{Ca}$ in the tympana being lower ( $G$-test, $P<0.001$ ). There was no difference in this respect between Dotilla and Scopimera $(P=0.887)$.
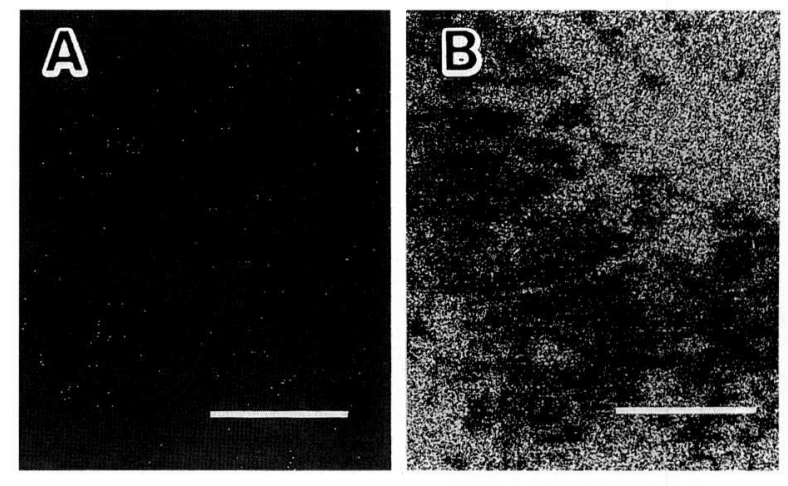

\section{DISCUSSION}

Both Dotilla myctiroides and Scopimera pilura are hyper-osmoregulators, and the osmoregulatory ability of the latter species is stronger than that of the former

Fig. 4. Silver distributions on the silver-stained tympana of the 3rd ambulatory legs of Scopimera pilura (A) and Dotilla myctiroides (B). The white dots show silver detected by energy-dispersive X-ray analysis, and the detected silver indicates leaks of chloride ions from the tissue. Scale bar $=20 \mu \mathrm{m}$. 

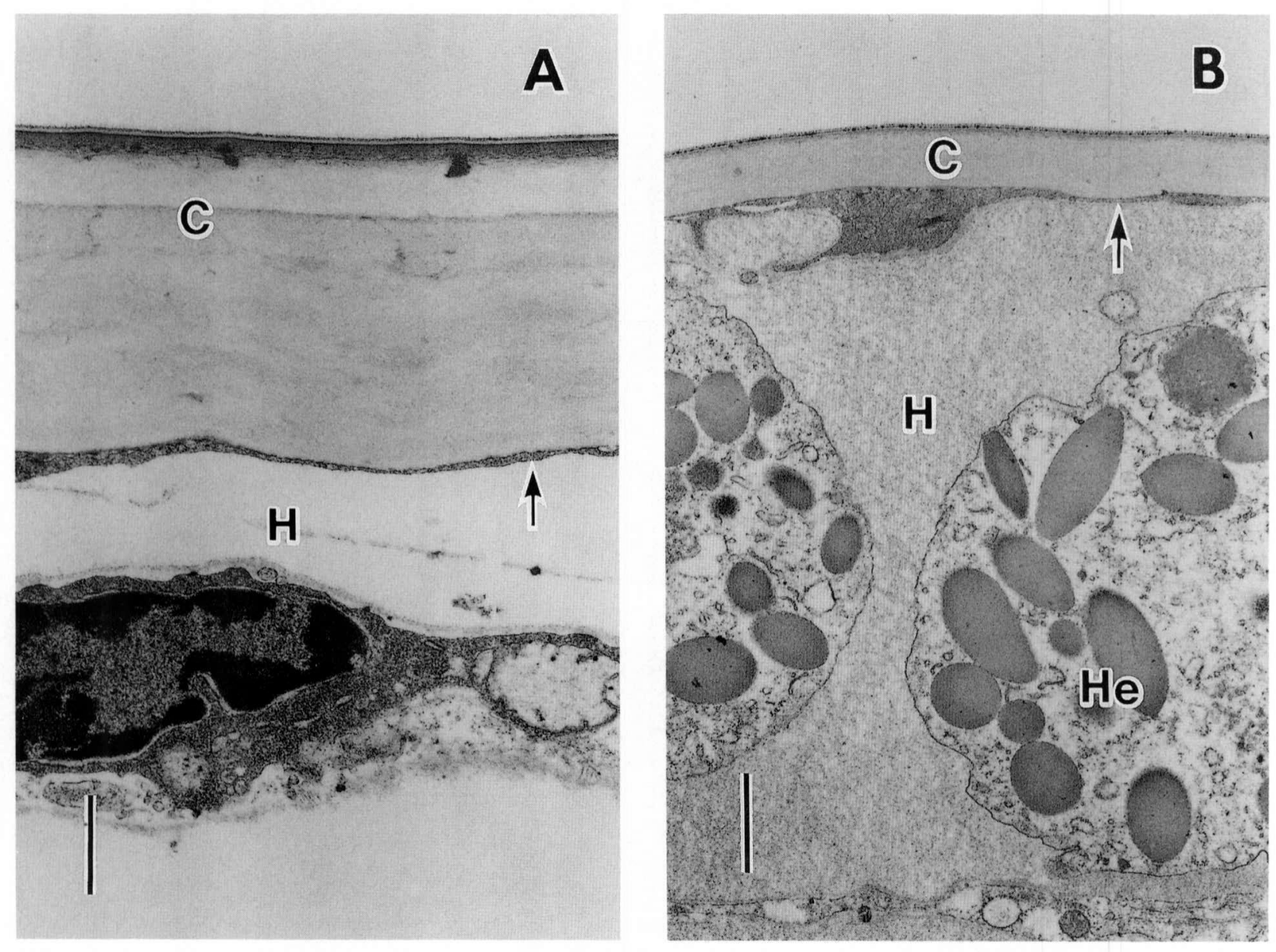

Fig. 5. TEM of the leg tympana of Scopimera pilura (3rd ambulatory leg; A) and Dotilla myctiroides (2nd ambulatory leg; B). The epithelia (arrows) are quite thin and have few intracellular organelles in both species. C, cuticle; H, hemocoel; He, hemocyte. Scale bar $=1 \mu \mathrm{m}$.

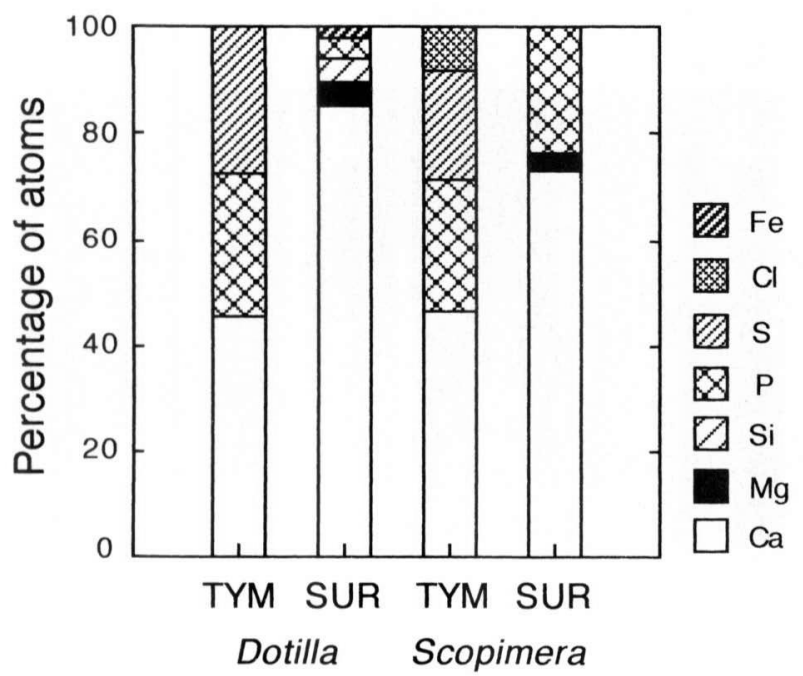

Fig. 6. Relative abundances of elements in tympana (TYM) and surrounding cuticles (SUR) of Dotilla myctiroides and Scopimera pilura. Percentages of atoms were calculated for the seven elements that were detected by energy dispersive X-ray analyses. in dilute media (Fig. 2). This coincides with the fact that, in the tropical Indo-West Pacific, species of Scopimera generally inhabit higher levels of sandy shores than do species of Dotilla (MacNae \& Kalk 1962; Silas \& Sankarankutty 1967; Hartnoll 1973; Matsumasa et al. 1992; Takeda et al. 1996b). Higher up, rainfall and other freshwater inflow of ten reduce the environmental salinity.

Our histological results showed that the epithelia of the tympana of Dotilla and Scopimera are thin, simple, respiratory surfaces with few mitochondria and covered with relatively thin and weakly calcified cuticle layers (Fig. 5). Although some other types of respiratory organs including gills often function as osmoregulatory sites in intertidal, brackish, and freshwater crustaceans (Mantel \& Farmer 1983; Gilles \& Péqueux 1985; Péqueux \& Gilles 1988; Kikuchi \& Matsumasa 1997), the tympana do not. The tympana are exposed directly to air during surface activities, while the gills of semi-terrestrial crabs are in branchial chambers, 
into which urine is excreted from antennal glands and external water is taken up from the substrate through specialized setae at the bases of the walking legs (see Greenaway 1988; Farrelly \& Greenaway 1992). These differences in localization of the respiratory organs suggest that the tympana would be less suitable sites for ion transport than the gills. As a result, without ion-transporting epithelia, the tympanal areas would be one of the most probable sites for ion-loss from the body in dilute external media. In fact, the results of silver staining revealed that in Dotilla, the tympanal area is more permeable to $\mathrm{Cl}^{-}$than the surrounding body surface (Fig. 3). However, the tympana of the two examined species of Scopimera were scarcely stained at all, indicating that they were far less permeable than the leg and thoracic tympana of Dotilla (Figs. 3, 4). Although the silver-staining method has usually been used to identify ion-transporting surfaces by staining these more darkly than ordinary respiratory surfaces, the absence of any ion-transporting epithelia in the tympana of Dotilla shows that the stained area does not always function as an osmoregulatory site. As mentioned in some previous studies (Farrelly \& Greenaway 1992; Kikuchi 1992; Kikuchi \& Matsumasa 1993b), the cell types underlying silver-stained areas should always be identified ultrastructurally. As physiological adaptations in brackish and freshwater crustaceans, Lockwood \& Bolt (1989) pointed out (1) the reduction in the permeability of the body surface to water/ions and (2) the improvement of effectiveness in ion uptake from low external salinities. The less-stained tympana of S. pilura and S. proxima with simple respiratory epithelia are involved with consideration (1) above, whereas gills with ion-transporting epithelia in some semi-terrestrial crabs (e.g. Takeda et al. 1996a) are concerned with consideration (2).

The thickness and density of the cuticle (e.g. the degree of calcification) are considered to be particularly important variables with respect to water/ion permeability, because the well-developed surface layer of lipids typical of insects has not been observed in crustaceans (Greenaway 1988). The tympanal cuticles of the two species of Scopimera were significantly thicker than that of Dotilla myctiroides (Bonferroni test: $P<$ 0.001) (Table 1), in accordance with the differences in silver staining between the species. On the other hand, the relative percentage of $\mathrm{Ca}$ was not significantly different between the tympanal areas of Dotilla and Scopimera ( $G$-test: $P=0.887$ ), although the values were much lower than those for the normal exoskeleton of the legs (Fig. 6). These results indicate that cuticle thickness is a more important variable with respect to the tympanal permeability than the degree of cuticle calcification is. The extremely thin $(0.8 \mu \mathrm{m})$ cuticle of the leg tympana of D. myctiroides is comparable with those of gills and lungs in the branchial chambers of semi-terrestrial crabs (Maitland 1986; McMahon \& Burggren 1988; Kikuchi 1992; Takeda et al. 1996a). An Australian sand bubbler, Scopimera inflata, also has extremely thin $(0.6 \mu \mathrm{m})$ cuticle in its leg tympana (Maitland 1986). But S. pilura and S. proxima in this study have much thicker cuticles $(>3.5 \mu \mathrm{m})$. Hence, there appears to be some degree of variation in thickness of tympanal cuticles among species of the same genus. This should be examined more closely, together with an examination of the relationships between osmoregulatory ability and habitat characteristics (e.g. elevation, salinity, and sediment conditions).

The thicker, relatively less permeable tympana of Scopimera pilura and S. proxima have an advantage over those of Dotilla myctiroides in maintaining its blood osmolality. A thick tympanum is probably important for reducing not only the loss of ions from crab bodies in dilute media, but also the loss of water during aerial activities in arid environments (Greenaway 1988). However, the resultant longer blood/gas diffusion distances for the leg tympana of S. pilura and $S$. proxima (Table 1) no doubt also result in lower airbreathing efficiency and a reduced absolute contribution of the tympana to aerial gas exchange (see Farrelly \& Greenaway 1992 for gills). The blood/gas diffusion distances for these species of Scopimera are more than four times longer than that $(0.9 \mu \mathrm{m})$ for leg tympana of $D$. myctiroides, which is comparable to those $(<1 \mu \mathrm{m})$ for respiratory gills (not osmoregulatory ones) and for lungs of similar-sized crabs (Maitland 1986; McMahon \& Burggren 1988). This possible trade-off between efficiency in air breathing and in water/ion retention, which is related mainly to the cuticle thickness of the tympana, indicates a physiological limitation for the tympana as air-breathing organs in semi-terrestrial environments where the influence of reduced salinity is potent. That is, the gas window that had evolved and developed during the invasion from marine to land habitats may be degenerative in some euryhaline, higher-shore species of the subfamily Dotillinae. From this viewpoint, another genus of Dotillinae, Ilyoplax, is interesting, because this genus includes both species with and without tympana on their legs (Kemp 1919). Recently, based on analyses of 1,416-base-pair nucleotide sequences from the mitochondrial $12 \mathrm{~S}$ to $16 \mathrm{~S}$ rRNA genes, Kitaura et al. 
(1998) figured the relationships between 21 species of the family Ocypodidae, including 15 species of the subfamily Dotillinae, in a phylogenetic tree. Although they did not mention the distribution of tympana among the species of Dotillinae, their excellent study revealed some important phylogenetic relationships. For example, Dotilla wichmanni, a species close to $D$. myctiroides in this study, formed a clade with an Ilyoplax lineage in which the species do not possess any gas windows (see Serene \& Lundoer 1974). Since $D$. wichmanni is the most basal among the species in the clade, it is supposed that the Ilyoplax species without tympana might be derived from an ancestral species with tympana. Without the knowledge of the tympanal function, Kemp (1919) had already stated, "Most of the species of Dotilla and Scopimera live on the seashore. ... Most species of Tympanomerus [= Ilyoplax] are found in estuaries, of ten near or even beyond the extreme limit of tide influences. Both species of Dotillopsis are essentially estuarine, ..." and, "The tympana are well-defined and usually conspicuous in Scopimera and Dotilla, ill-defined in Dotillopsis and illdefined or absent in Tympanomerus." The ill-defined tympana of Dotillopsis brevitarsis has a thicker (ca. 6$7 \mu \mathrm{m}$ ) cuticle than the tympana of Dotilla and Scopimera, which are associated with similar simple respiratory epithelia (Matsumasa et al., unpublished data). Therefore, the increase in cuticle thickness would make tympana appear ill-defined. If a fully resolved phylogenetic tree were available for this subfamily, we believe that more detailed investigations of relationships between degrees of tympanal development/degeneration and the functional significance of tympana (e.g. contributions of the gas windows vs. gills/lungs to total oxygen consumptions) in various habitats will provide us with further insights.

Acknowledgments. We are very grateful to the staff of the Phuket Marine Biological Center and the Department of Zoology, Faculty of Scieıce, University of Malaya, for their kindness and cooperation. We express sincere thanks to Mr. Yasuo Yoshida, Laboratory of Electron Microscopy, Iwate Medical University, for his kind help in X-ray analyses. A friend of the first author, Mr. Richard Donaldson, Iwate Medical University, and anonymous reviewers gave us helpful comments. This study was supported by a Grant-in-Aid for International Scientific Research from the Japan Ministry of Education, Science, Sports and Culture (No. 01041069).

\section{REFERENCES}

Barra, J. A., A. Péqueux and W. Humbert 1983. A morphological study on the gills of a crab acclimated to fresh water. Tissue \& Cell, 15: 1-5.

Bliss, D. E. 1979. From sea to tree: Saga of a land crab. American Zoologist, 19: 385-410.

Dickson, J. S., R. M. Dillaman, R. D. Roer and D. B. Roye 1991. Distribution and characterization of ion transporting and respiratory filaments in the gills of Procambarus clarkii. Biological Bulletin, 180: 154-166.

Farrelly, C. A. and P. Greenaway 1992. Morphology and ultrastructure of the gills of terrestrial crabs (Crustacea, Gecarcinidae and Grapsidae): adaptations for air-breathing. Zoomorphology, 112: 39-49.

Gilles, R. and A. Péqueux 1985. Ion transport in crustacean gills: physiological and ultrastructural approaches. In, Transport Process, Iono- and Osmoregulation, Gilles, R. and M. Gilles-Baillien (eds.), Springer-Verlag, Berlin, pp. 136-158.

Greenaway, P. 1988. Ion and water balance. In, Biology of the Land Crabs, Burggren, W. W. and B. R. McMahon (eds.), Cambridge University Press, Cambridge, pp. 211-248.

Hartnoll, R. G. 1973. Factors affecting the distribution of the crab Dotilla fenestrata on East African shores. Estuarine and Coastal Marine Science, 1: 137-152.

Kemp, S. 1919. Notes on Crustacea Decapoda in the Indian Museum-Scopimerinae. Records of the Indian Museum, 16: 305-348.

Kikuchi, S. 1992. The relationship between the ultrastructure of the gill epithelia and the environmental salinities in crustaceans. Comparative Physiological Biochemistry, 9: 129-140 (in Japanese).

Kikuchi, S. and M. Matsumasa 1993a. Two ultrastructurally distinct types of transporting tissues, the branchiostegal and the gill epithelia, in an estuarine tanaid, Sinelobus stanfordi (Crustacea, Peracarida). Zoomorphology, 113: 253-260.

Kikuchi, S. and M. Matsumasa 1993b. The osmoregulatory tissue around the afferent blood vessels of the coxal gills in the estuarine amphipods, Grandidierella japonica and Melita setiflagella. Tissue \& Cell, 25: 627-638.

Kikuchi, S. and M. Matsumasa 1995. Pereopodal disk: a new type of extrabranchial ion-transporting organ in an estuarine amphipod, Melita setiflagella (Crustacea). Tissue \& Cell, 27: 635-643.

Kikuchi, S. and M. Matsumasa 1997. Ultrastructural evidence for osmoregulatory function of the sternal epithelia in some gammaridean amphipods. Journal of 
Crustacean Biology, 17: 377-388.

Kitaura, J., K. Wada and M. Nishida 1998. Molecular phylogeny and evolution of unique mud-using territorial behavior in ocypodid crabs (Crustacea: Brachyura: Ocypodidae). Molecular Biology and Evolution, 15: 623637.

Lockwood, A. P and S. R. L. Bolt 1989. Physiology of Crustacea from difficult environments. Transactions of the Royal Society of Edinburgh: Earth Sciences, 80: 285292.

Macintosh, D. J. 1979. The Ecology and Energetics of Mangrove Fiddler Crabs (Uca spp.) on the West Coast of the Malay Peninsula. Ph. D. Dissertation, University of Malaya, Kuala Lumpur, 332 pp.

MacNae, W. and M. Kalk 1962. The fauna and flora of sand flats at Inhaca Island, Mozambique. Journal of Animal Ecology, 31: 93-128.

Maitland, D. P. 1986. Crabs that breathe air with their legs - Scopimera and Dotilla. Nature, 319: 493-495.

Maitland, D. P. and A. Maitland 1992. Penetration of water into blind-ended capillary tubes and its bearing on the functional design of the lungs of soldier crabs Mictyris longicarpus. Journal of Experimental Biology, 163: 333-344.

Mantel, L. H. and L. L. Farmer 1983. Osmotic and ionic regulation. In, The Biology of Crustacea. Vol. 5: Internal Anatomy and Physiological Regulation, Mantel, L. H. (ed.), Academic Press, New York, pp. 53-161.

Matsumasa, M., S. Kikuchi and I. Takeuchi 1998. Specialized ion-transporting epithelium around the blood vessel of the coxal gills in a deep-sea amphipod, Eurythenes gryllus. Journal of Crustacean Biology, 18: 686-694.

Matsumasa, M., S. Takeda, S. Poovachiranon and M. Murai 1992. Distribution and shape of Dotilla myctiroides (Brachyura: Ocypodidae) burrow in the seagrass Enhalus acoroides zone. Benthos Research, 43: 1-9.

McLusky, D. S. 1968. Aspects of osmotic and ionic regulation in Corophium volutator (Pallas). Journal of the Marine Biological Association of the United Kingdom, 48: 769-781.
McMahon, B. R. and W. W. Burggren 1988. Respiration. In, Biology of the Land Crabs, Burggren, W. W. and B. R. McMahon (eds.), Cambridge University Press, Cambridge, pp. 249-297.

Péqueux, A and R. Gilles 1988. $\mathrm{NaCl}$ transport in gills and related structures. Part I: Invertebrates. In, Advances in Comparative \& Environmental Physiology. Vol. 1, Greger, R. (ed.), Springer-Verlag, Berlin, pp. 247.

Powers, L. W. and D. E. Bliss 1983. Terrestrial adaptations. In, The Biology of Crustacea Vol. 8: Environmental Adaptation, Vernberg, F. J. and W. B. Vernberg (eds.), Academic Press, New York, pp. 271334.

Serene, R. and S. Lundoer 1974. Observations on the male pleopod of the species of Ilyoplax Stimpson with a key to the identification of the species. Phuket Marine Biological Center, Research Bulletin, 3: 1-10.

Silas, E. G. and C. Sankarankutty 1967. Field investigations on the pellet crab Scopimera proxima Kemp. Marine Biological Association of India Symposium Series, 2: 1008-1025.

Takeda, S., M. Matsumasa, S. Kikuchi, S. Poovachiranon and M. Murai 1996a. Variation in the branchial formula of semiterrestrial crabs (Decapoda: Brachyura: Grapsidae and Ocypodidae) in relation to physiological adaptations to the environment. Journal of Crustacean Biology, 16: 472-486.

Takeda, S., M. Matsumasa, H.-S. Yong and M. Murai 1996b. "Igloo" construction by the ocypodid crabs, Dotilla myctiroides (Milne-Edwards) (Crustacea: Brachyura): the role of an air chamber when burrowing in a saturated sandy substratum. Journal of Experimental Marine Biology and Ecology, 198: 237-247.

Tsubokura, T., S. Kikuchi and S. Nakao 1998. Distribution pattern, gill area relationships, and fine structural characteristics of the gill epithelia in supralittral and terrestrial talitrid amphipods. Journal of Crustacean Biology, 18: 625-642.

Wilkinson, L. 1992. SYSTAT, version 5.2 edition. SYSTAT, Inc., Evanston, Illinois, 724 pp. 